\title{
Ultrasound-Guided Bilateral Greater Occipital Nerve Block for the Treatment of Postdural Puncture Headache
}

\author{
Fethi Akyol, Orhan Binici, Mahmut Çakır \\ Department of Anaesthesiology and Reanimation, Erzincan State Hospital, Erzincan, Turkey
}

\begin{abstract}
Treatment of postdural puncture headaches involves oral or intravenous (IV) fluid or caffeine-containing analgesics, micro-catheterization of spinal space, epidural administration of blood obtained from the patient, or epidural blood patch and fiberoptic imaging-guided epidural interventional techniques. Epidural blood patch is, to date, the most effective treatment, but it is an invasive procedure that may result in serious complications. Spinal anaesthesia was planned for a 22 year old male patient diagnosed with inguinal hernia and for a 42 year old female patient diagnosed with venous stasis. On the first post-operative day, the patients with a postdural puncture headache received conservative medical treatment. As medical treatment was ineffective, they received ultrasound-guided greater bilateral occipital nerve block. In this case report, the effect of the ultrasound-guided bilateral greater occipital nerve block on postdural puncture headache is discussed.
\end{abstract}

Key Words: Postdural puncture headache, nerve block, ultrasound

\section{Introduction}

he major disadvantage of dural laceration for a patient is the postdural puncture headache (PDH), which may commonly occur (1). Classical symptoms of PDH due to dural laceration include photophobia, nausea, vomiting, neck stiffness, tinnitus, diplopia, vertigo, and serious headache. Headache is intensive and pulsatile, begins from frontal region and extends to occipital region and worsens in sitting and standing positions $(2,3)$. Sudden decrease in cerebrospinal fluid (CSF) pressure causes extension of pain-sensitive structures such as dura mater, cerebral arteries, and venous sinuses and headache manifests clinically $(4,5)$. Greater occipital nerve contains sensory fibres from C2 and C3 segments of medulla spinalis. It arises from the dorsal ramus of C2 segment, contains a thin branch from C3 segment, and innerves the medial aspect of posterior scalp up to the anterior aspect of vertex. Grater occipital nerve block inhibits the pain sensation of this region (6).

\section{Case Presentations}

\section{Case 1}

Surgery was planned in a 22-year-old male patient for inguinal hernia. After obtaining his consent, spinal anaesthesia was planned for the patient, who was in the American Society of Anaesthesiologists (ASA) I risk group with no pathological laboratory values or concomitant disease. An intravenous (IV) vascular access was obtained and $10 \mathrm{~mL} \mathrm{~kg} 0.9 \% \mathrm{NaCl}$ infusion was initiated. The patient was referred to the operating room following premedication with administration of midazolam $0.15 \mathrm{mg} \mathrm{kg}^{-1} \mathrm{IV}$. He was monitored in terms of noninvasive blood pressure, electrocardiography (ECG), heart rate, and peripheral oxygen saturation. Following disinfection of the region in lateral recumbent position, intratechal space was accessed passing through the L3 and L4 intervertebral space using 25 gauge (G) Quincke spinal needle. After observing CSF flow, spinal anaesthesia was performed using $15 \mathrm{mg}$ hyperbaric bupivacaine (Marcaine spinal heavy $3 \mathrm{~mL} 0.5 \%$ ampoule for injection, Astra Zeneca) +15 mcg fentanyl. Haemodynamic parameters of the patient were stable both during and after the surgery. After the surgery, the patient was informed about lying in supine position and drinking plenty of fluid. On the first postoperative day, the patient developed PDH, which was worsening in upright position and accompanied by nausea. Supine position, oral caffeinated analgesics, and daily $3000 \mathrm{cc}$ fluid intake were recommended. His complaints did not relieve until postoperative fourth day despite treatment. The patient underwent ultrasonographic examination via plane probe 
performed through the superior nuchal line and greater occipital nerve was visualized (Figure 1). Under ultrasonographic guidance, $4 \mathrm{~mL}$ local anaesthetic (1\% lidocaine) was injected around the right and left greater occipital nerve (Figure 2). Headache relieved approximately in a minute and the patient was discharged after 24 hours without problem.

\section{Case 2}

Surgery under spinal anaesthesia was planned for venous insufficiency in the right leg of a 42-year-old female patient, who was in ASA I risk group with no pathological finding in the previous laboratory values and no concomitant disease. An intravenous vascular access was obtained through the dorsal aspect of the right hand using $18 \mathrm{G}$ branule and $10 \mathrm{~mL}$ $\mathrm{kg}^{-1} 0.9 \% \mathrm{NaCl}$ infusion was initiated. After premedication with midazolam $0.15 \mathrm{mg} \mathrm{kg}^{-1} \mathrm{IV}$, the patient was referred to the operating room. She was monitored in terms of noninvasive blood pressure, ECG, heart rate, and peripheral oxygen saturation. Following the disinfection of waist region in sitting position, intratechal space was accessed passing through the L3 and L4 intervertebral space using 25 G Quincke spinal needle. After observing CSF flow, spinal anaesthesia was performed using $15 \mathrm{mg}$ hyperbaric bupivacaine (Marcaine spinal heavy $3 \mathrm{~mL} \mathrm{0.5 \%} \mathrm{ampoule} \mathrm{for} \mathrm{injection,} \mathrm{Astra} \mathrm{Zeneca)}$ $+15 \mathrm{mcg}$ fentanyl. On the postoperative first day, she develo-

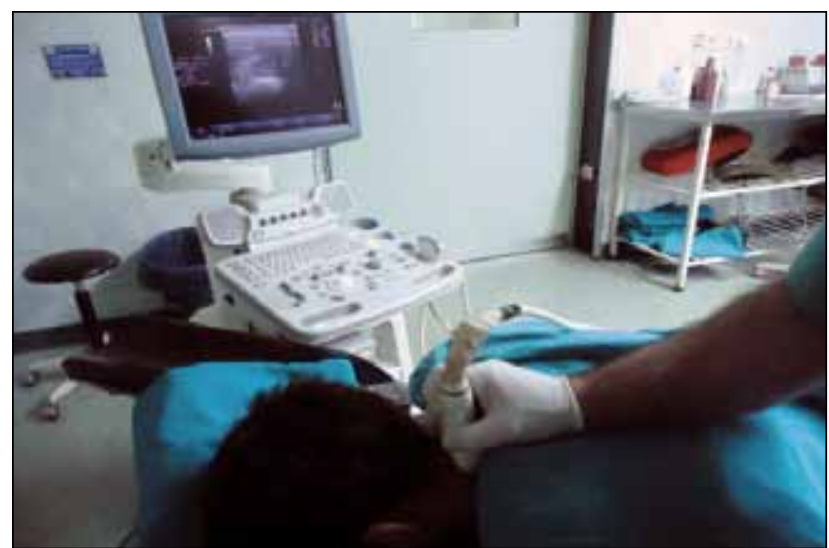

Figure 1. Observing greater occipital nerve via plane probe through the superior nuchal line

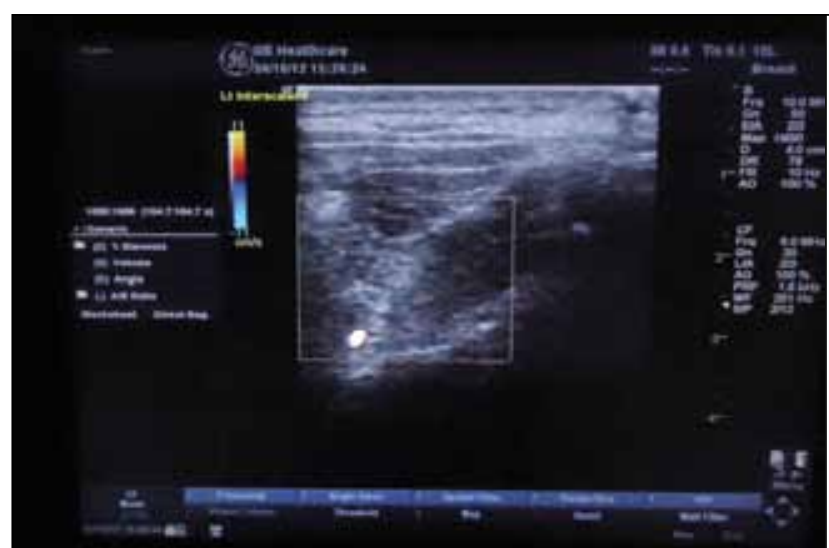

ped $\mathrm{PDH}$, which was beginning from frontal and extending to the occipital aspect and worsening in upright position and accompanied by neck stiffness. Lying in supine position, oral caffeinated analgesics, and daily $3000 \mathrm{cc}$ fluid intake were recommended. The patient, whose complaints did not relieve until the postoperative fourth day despite treatment, underwent ultrasonographic examination performed via plane probe through the superior nuchal line and greater occipital nerve was observed (Figure 2). Under ultrasonographic guidance, $4 \mathrm{~mL}$ local anaesthetic (1\% lidocaine) was injected around the right and left greater occipital nerve. Headache relieved in 1-2 minutes and the patient was discharged after 24 hours without problem.

\section{Discussion}

The incidence of PDH increases in young patients, females, with the use of sharp-ended thick needles, and in the cases with multiple holes in dura (7). Treatment of PDH include oral or IV fluid replacement, caffeinated analgesics, microcatheter application into the spinal space, epidural blood patch (obtaining blood from patient and giving into the epidural space), and fibre-optic image-guided epidural interventions (8).

Nociceptive stimulations arising from the meninges in the cervical region sensitize convergent neurons in the posterior horn at $\mathrm{C} 2$ level; since the branch of greater occipital nerve arising from $\mathrm{C} 2$ root is responsible for the innervation of deep paraspinal muscles and suboccipital configurations, greater occipital nerve blockade inhibits the stimulations arising from these regions innervated by the greater occipital nerve (9). Greater occipital nerve has superficial location leading to lesser complications; however, there is intravascular injection risk, which can be prevented by careful aspiration. Patients should be questioned for previous intracranial trauma or cranial defect to reduce likely complications (10). In a previously published case report, bilateral occipital nerve blockade was safely performed in 2 patients with PDH and pain was relieved within a few minutes (6). In another case report, patient with PDH underwent bilateral occipital nerve blockade and

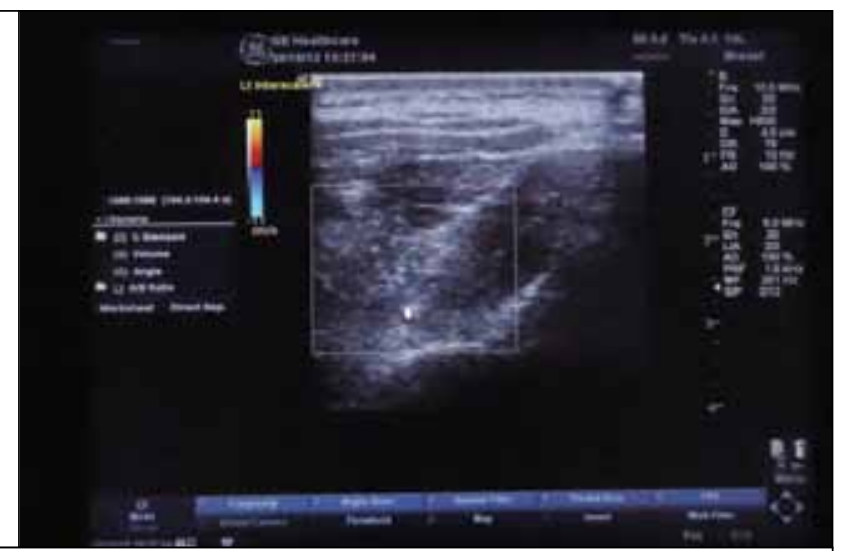

Figure 2. Ultrasonographic view of occipital nerve region where the injection was applied 
pain was relieved in approximately 2 minutes; however, it recurred 12 hours later and blockade was repeated (11). In a randomized controlled study comprising 50 patients, complete analgesia was achieved in $68 \%$ of the patients after the first or second bilateral occipital blockade. Pain management was more successful and duration of hospital stay was shorter in the patients as compared to the control group (12).

Epidural blood patch method was defined more than 40 years ago and has remained as the most effective method in the treatment of PDH (13). Lumbo-vertebral syndrome characterized by temporary bradycardia and facial paralysis has been reported due to epidural blood patch $(14,15)$. Another study reported a case who underwent epidural blood patch procedure for six times, developed cauda equina syndrome, and achieved full recovery with treatment (16). Although epidural blood patch is used as an effective treatment method after conservative medical treatments in $\mathrm{PDH}$, we preferred ultrasound-guided bilateral occipital nerve block in both cases due to low risk of complication since epidural blood patch is an invasive method and has the risk of complications such as neurological sequelae, radiculopathy, spinal-subdural hematoma, spinal-epiarachnoid hematoma, intratechal hematoma, arachnoiditis, and infection (11). Bilateral greater occipital nerve block was successfully performed in both cases without any complication. Since recurrence of headache was not observed during 24 hour monitoring, the patients were discharged without problem.

\section{Conclusion}

Ulrasound-guided bilateral greater occipital nerve blockade with low risk of complication can be safely performed after conservative medical treatments for PHD instead of invasive treatment methods that have various complications. We suggest that further controlled studies are needed for this method to be used more safely and frequently.

Informed Consent: Written informed consent was obtained from patients who participated in this case.

Peer-review: Externally peer-reviewed.

Author Contributions: Concept - F.A., O.B.; Design - O.B., M.Ç.; Supervision - F.AProcessing - O.B., F.A., M.Ç.; Analysis and/or Interpretation - F.A.; Literature Review - O.B.; Writer - O.B.; Critical Review - O.B., FA.

Conflict of Interest: No conflict of interest was declared by the authors.

Financial Disclosure: The authors declared that this case has received no financial support.

\section{References}

1. Bezov D, Lipton RB, Ashina S. Post-dural puncture headache: part I diagnosis, epidemiology, etiology, and pathophysiology. Headache 2010; 50: 1144-52. [CrossRef]

2. Chan TM, Ahmed E, Yentis SM, Holdcroft A; Obstetric Anaesthetists' Association; NOAD Steering Group. Postpartum headaches: summary report of the National Obstetric Anaesthetic Database (NOAD) 1999. Int J Obstet Anesth 2003; 12: 107-12. [CrossRef]

3. Güngör İ, Günaydın B, Taş A, Dayanır H, Altınsoy A. Postspinal tinnitus requiring treatment: Efficacy of epidural blood patch. Turkiye Klinikleri J Med Sci 2012; 32: 515. [CrossRef]

4. Hess JH. Postdural puncture headache: A literature review. AANA J 1991; 59: 549-55.

5. Turnbull DK, Shepherd DB. Post-dural puncture headache: Pathogenesis, prevention and treatment. Br J Anaesth 2003; 91: 718-29. [CrossRef]

6. Matute E, Bonilla S, Girones A, Planas A. Bilateral greater occipital nerve block for post-dural puncture headache. Anaesthesia 2008; 63: 557-8. [CrossRef]

7. Schmittner MD, Terboven T, Dluzak M, Janke A, Limmer $\mathrm{ME}$, Weiss $\mathrm{C}$, et al. High incidence of post-dural puncture headache in patients with spinal saddle block induced with $\mathrm{Qu}-$ incke needles for anorectal surgery: a randomised clinical trial. Int J Colorectal Dis 2010; 25: 775-81. [CrossRef]

8. Saraçoğlu K.T, Saraçoğlu A, Çelik M. Anesthesia management after inadvertent dural puncture during application of epidural blockage. Dicle Medical Journal 2010; 37: 394-6.

9. Selekler MH. Greater occipital nerve blockade: trigeminicervical system and clinical applications in primary headaches. Agri 2008; 20: 6-13.

10. Okuda Y, Matsumoto T, Shinohara M, Kitajima T, Kim P. Sudden unconsciousness during a lesser occipital nerve block in a patient with the occipital bone defect. Eur J Anaesthesiol 2001; 18: 829-32. [CrossRef]

11. Akin Takmaz S, Unal Kantekin C, Kaymak C, Başar H. Treatment of post-dural puncture headache with bilateral greater occipital nerve block. Headache 2010; 50: 869-72. [CrossRef]

12. Naja Z, Al-Tannir M, El-Rajab M, Ziade F, Baraka A. Nerve stimulator-guided occipital nerve blockade for postdural puncture headache. Pain Pract 2009; 9: 51-8. [CrossRef]

13. Miller RD, Fleisher LA, Johns RA, Savarese JJ, Young WL. Complicati- ons of spinal anesthesia. Miller Anesthesia 6th Ed 2010; 58: 2328-30.

14. Andrews PJ, Ackerman WE, Juneja M, Cases-Cristobal V, Rigor BM. Transient bradycardia associated with extradural blood patch after inadvertent dural puncture in parturients. $\mathrm{Br}$ J Anaesth 1992; 69: 401-3. [CrossRef]

15. Seeberger MD, Urwyler A. Lumbovertebral syndrome after extradural blood patch. Br J Anaesth 1992; 69: 414-6. [CrossRef]

16. Tekkok IH, Carter DA, Brinker R. Spinal subdural haematoma as a complication of immediate epidural blood patch. Can J Anaesth 1996; 43: 306-9. [CrossRef] 